\title{
Sonochemical synthesis of $\mathrm{ZnO}$ nanotubes and their optical emissions
}

\author{
Chat PHOLNAK, Chitnarong SIRISATHITKUL ${ }^{\dagger}$ David James HARDING and Sumetha SUWANBOON*
}

\author{
Molecular Technology Research Unit, School of Science, Walailak University, Nakhon Si Thammarat 80160, Thailand \\ *Department of Materials Science and Technology, Faculty of Science, Prince of Songkla University, \\ Hat Yai, Songkhla, 90112, Thailand
}

\begin{abstract}
Hexagonal zinc oxide $(\mathrm{ZnO})$ nanotubes were synthesized from $0.05 \mathrm{M}$ zinc nitrate hexahydrate $\left[\mathrm{Zn}\left(\mathrm{NO}_{3}\right)_{2} \cdot 6 \mathrm{H}_{2} \mathrm{O}\right]$ and hexamethylenetetramine $\left(\mathrm{C}_{6} \mathrm{H}_{12} \mathrm{~N}_{4}\right)$ by a sonochemical method under ambient conditions. White precipitates, obtained after ultrasonic irradiation for $60 \mathrm{~min}$, were characterized by X-ray diffraction (XRD), scanning electron microscopy (SEM) and photoluminescence spectroscopy (PL). The $\mathrm{ZnO}$ crystals had a tubular structure $\sim 500 \mathrm{~nm}$ in length with a hexagonal cross section for both the inner and outer walls. The room temperature PL spectrum of ZnO nanotubes exhibited an ultraviolet (UV) emission peak, a sharp violet peak and a further broad visible band centered at $650 \mathrm{~nm}$.
\end{abstract}

(-2011 The Ceramic Society of Japan. All rights reserved.

Key-words : ZnO nanotubes, Sonochemical method, Photoluminescence, Near band-edge recombination, Oxygen vacancy

[Received February 17, 2011; Accepted March 29, 2011]

Micro- and nano-scale tubular structures have attracted extensive interest due to their unique hollow morphology with space confined transport properties, large surface area and potential applications in nanotechnology. Since the discovery of carbon nanotubes, ${ }^{1)}$ such structures have been fabricated using many different compounds including zinc oxide $(\mathrm{ZnO})$. $\mathrm{ZnO}$ microtubes with well faceted surfaces have been successfully synthesized by chemical solution techniques, ${ }^{2)}$ thermal evaporation, ${ }^{3)}$ hydrothermal methods, ${ }^{4)}$ and direct microwave heating. ${ }^{5)}$

With the rapid development in ultrasonic sonochemistry, a variety of chemical reactions can acquire energy from the process of acoustic cavitations driven by ultrasound waves involving the formation, growth and implosive collapse of bubbles in the liquid. ${ }^{6}$ The process is generally simple and requires low-cost setups with moderate energy demand. The sonochemical method is therefore a real alternative for producing $\mathrm{ZnO}$ of varying morphologies. Ultrasound pretreatments prior to solution synthesis and an ultrasonically assisted 2-step polyol process have previously been shown to enable the formation of $\mathrm{ZnO}$ tubes. ${ }^{2), 7)}$ In this work, $\mathrm{ZnO}$ hexagonal nanotubes were prepared by a sonochemical method. Their morphological and optical properties were then examined.

Reagent grade zinc nitrate hexahydrate $\left[\mathrm{Zn}\left(\mathrm{NO}_{3}\right)_{2} \cdot 6 \mathrm{H}_{2} \mathrm{O}\right]$ and hexamethylenetetramine $\left(\mathrm{C}_{6} \mathrm{H}_{12} \mathrm{~N}_{4}\right)$ powders $(\geq 99.0 \%$ in purity) were used as starting materials without any pretreatment. The solution, $0.05 \mathrm{M}$ in $\mathrm{Zn}\left(\mathrm{NO}_{3}\right)_{2} \cdot 6 \mathrm{H}_{2} \mathrm{O}$ and $\mathrm{C}_{6} \mathrm{H}_{12} \mathrm{~N}_{4}$ in $50 \mathrm{ml}$ deionized water, was prepared and stirred for $10 \mathrm{~min}$ with heating up to $50^{\circ} \mathrm{C}$ until a stable viscous white colloid formed. The colloid was then transferred to a vertical cylindrical glass vessel and placed in a $30 \mathrm{~W}$ ultrasonic reactor. It was sonicated at $35 \mathrm{kHz}$ for $1 \mathrm{~h}$ under ambient conditions. During the ultrasonic irradiation, the temperature of the colloid rose to approximately $70^{\circ} \mathrm{C}$. After the reaction was complete, the white precipitate was collected by filtration and thoroughly rinsed with distilled water and ethanol. Finally, the precipitate was dried in an oven at $60^{\circ} \mathrm{C}$

\footnotetext{
Corresponding author: C. Sirisathitkul; E-mail: schitnar@wu.ac.th
}

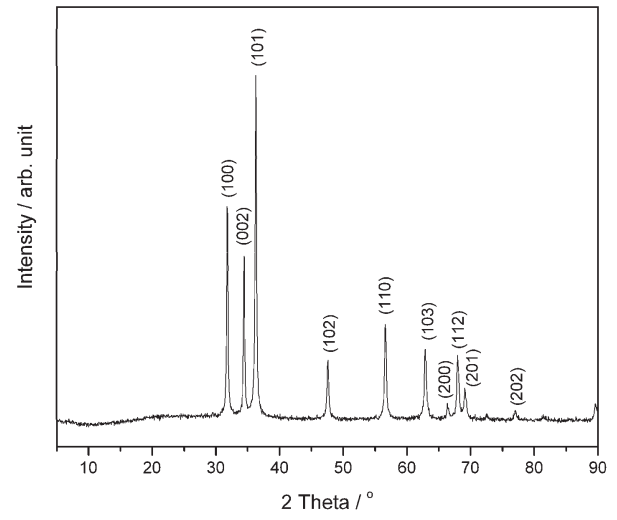

Fig. 1. XRD pattern of the product synthesized by sonochemical method.

in an air atmosphere. The crystallographic structure and morphology of the product were respectively examined by X-ray diffraction (XRD, Philips X'Pert MPD) with $\mathrm{CuK} \alpha$ radiation $(\lambda=1.5406 \AA)$ and scanning electron microscopy (SEM, FEI Quanta 400) operating at $25 \mathrm{kV}$. The room temperature photoluminescence (PL) spectrum was measured using a luminescence spectrometer (LS/55, PerkinElmer). The results were compared with those from samples prepared without ultrasonic irradiation.

The XRD pattern of the product from the sonochemical synthesis in Fig. 1 is identified as the hexagonal wurtzite $\mathrm{ZnO}$ structure. An SEM micrograph in Fig. 2(a) shows the morphology of the $\mathrm{ZnO}$. The inset is a magnified image of the tubular clusters. Each tube is symmetrically formed with hexagonal cross sections for both the inner and outer walls. The diameter of the tubes is on average around $260 \mathrm{~nm}$ and the length is ca. $500 \mathrm{~nm}$ making these amongst the smallest $\mathrm{ZnO}$ nantubes currently reported in the literature. ${ }^{2)-5), 7)}$ It has been proposed that $\mathrm{ZnO}$ tubular structures are formed from $\mathrm{ZnO}$ nuclei. Subsequent growth results in hexagonal nanorods around which an outer 

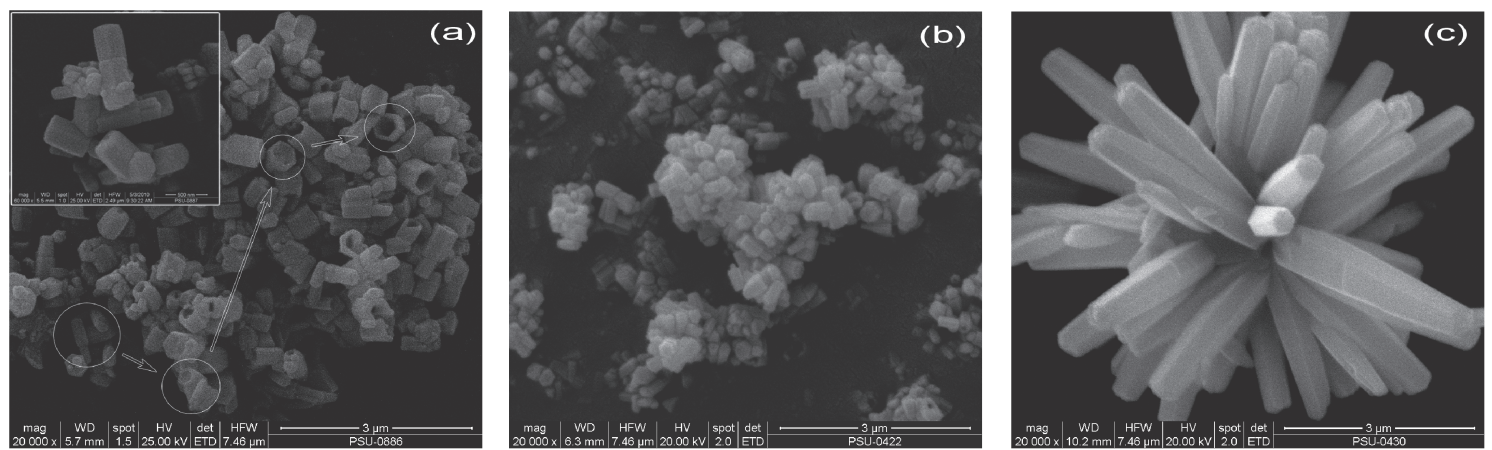

Fig. 2. SEM micrographs of $\mathrm{ZnO}$ products from $0.05 \mathrm{M} \mathrm{Zn}\left(\mathrm{NO}_{3}\right)_{2}-\mathrm{C}_{6} \mathrm{H}_{12} \mathrm{~N}_{4}$ aqueous solution after 60 min; (a) with sonication at $70^{\circ} \mathrm{C}$, (b) without sonication at $70^{\circ} \mathrm{C}$ and (c) without sonication at $90^{\circ} \mathrm{C}$.

layer grows causing decomposition of the inner nanorod. Continued growth eventually results in complete loss of the $\mathrm{ZnO}$ nuclei and hollow nanotubes. $\mathrm{ZnO}$ is known to grow fastest in the [0001] direction and thus the $\mathrm{ZnO}$ nanotubes tend to grow along the $c$-axis. ${ }^{3), 5)}$ This model is supported by Fig. 2(a) in which different morphologies from each growth step co-exist in our products. The series of circles indicate the growth step including the decomposition of the inner layers at the center of the hexagonal nanorods. Interestingly, with the same starting materials $\mathrm{Hu}$ et al. observed linked $\mathrm{ZnO}$ nanorods using a $20 \mathrm{kHz}$ sonicator for $30 \mathrm{~min}$, although the concentration of $\mathrm{Zn}\left(\mathrm{NO}_{3}\right)_{2}$ was $0.005 \mathrm{M}^{6)}$ It is clear that both the time and the frequency of sonication play a critical role in determining the morphology of the $\mathrm{ZnO}$ obtained. For the $\mathrm{ZnO}$ prepared from $0.05 \mathrm{M} \mathrm{Zn}\left(\mathrm{NO}_{3}\right)_{2}-$ $\mathrm{C}_{6} \mathrm{H}_{12} \mathrm{~N}_{4}$ aqueous solution at $70^{\circ} \mathrm{C}$ in the absence of sonication, hexagonal prisms without hollow cores were obtained as shown in Fig. 2(b). By increasing the temperature up to $90^{\circ} \mathrm{C}$, prismatic $\mathrm{ZnO}$ in Fig. 2(c) grows larger during the same $60 \mathrm{~min}$ period but its morphology remains different from that obtained by the sonochemical method indicating that sonication is vital in the preparation of $\mathrm{ZnO}$ nanotubes.

The room temperature PL spectrum of the hexagonal $\mathrm{ZnO}$ nanotubes is shown in Fig. 3. A UV emission peak and 2 peaks at both ends of the visible region are observed. The UV emission at $398 \mathrm{~nm}$ corresponds to the well-known near band-edge recombination of excitons. ${ }^{5), 6), 8)-10)}$ Visible emissions from $\mathrm{ZnO}$ are universally regarded as defect emissions from interstitial atoms and vacancies. ${ }^{9)}$ Different defect levels of oxygen vacancies were positioned beneath the conduction band. The narrow violet emission peak at $412 \mathrm{~nm}$ appears to originate from the transition between a shallow defect level and the valence band. Instead of the green emission often reported in literature, ${ }^{8)-11)}$ a broad visible peak centered around $650 \mathrm{~nm}$ (red) is observed in our $\mathrm{ZnO}$ product. It is of note that similar broad emission is also observed in $\mathrm{ZnO}$ microtubes, although the peak is centred at $485 \mathrm{~nm} .^{5)}$ This can be explained in terms of the difference in the growth conditions. It has been shown that different growth conditions affect the visible emissions via different morphologies and defects. ${ }^{10)}$ The broad visible peak in Fig. 3 is related to nanostructured $\mathrm{ZnO}$ with different morphologies from each growth step. The peak is shifted to the red emission because of deep defect levels well below the conduction band. Compared to a previous report on $\mathrm{ZnO}$ nanoparticles, the infrared and orange emissions were enhanced by annealing in an air atmosphere. ${ }^{12)}$ The intensity of this visible peak is stronger than that of the near band-edge UV emission peak, which suggests a high density of interstitial atoms and vacancies. Figure 3 also shows the PL

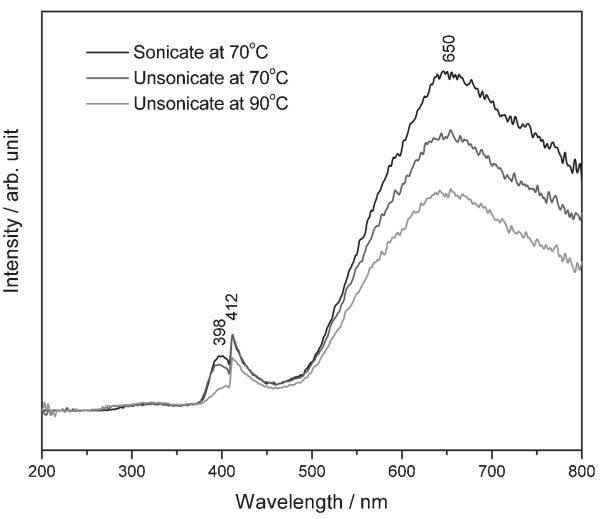

Fig. 3. Comparison of room temperature PL spectra of the sonochemical synthesized $\mathrm{ZnO}$ and $\mathrm{ZnO}$ products prepared without sonication.

spectra of $\mathrm{ZnO}$ from aqueous solution at 70 and $90^{\circ} \mathrm{C}$. Their optical emissions resemble that of sonochemical synthesized $\mathrm{ZnO}$ microtubes with peak shifts within $5 \mathrm{~nm}$. The intensity is, however, significantly reduced in the $\mathrm{ZnO}$ prepared at $90^{\circ} \mathrm{C}$ corresponding to the smaller surface-to-volume ratio of the larger prisms.

In summary, hexagonal $\mathrm{ZnO}$ nanotubes were obtained from the reaction between $\mathrm{Zn}\left(\mathrm{NO}_{3}\right)_{2} \cdot 6 \mathrm{H}_{2} \mathrm{O}$ and $\mathrm{C}_{6} \mathrm{H}_{12} \mathrm{~N}_{4}$ under an ultrasonic irradiation at $35 \mathrm{kHz}$ for $1 \mathrm{~h}$. Compared to the control experiments without sonication, the ultrasonic treatment proved to be effective in promoting active $\mathrm{ZnO}$ nuclei and growth of hexagonal tubes from active nanorods. The proposed growth mechanism was supported by SEM. In addition to a UV emission peak, an intense broad red emission band centered at $650 \mathrm{~nm}$ was identified in the PL spectrum.

Acknowledgements This work was funded by Walailak University (Grant WU53301). The XRD and SEM characterizations were carried out at the scientific equipment center and the PL spectra were obtained from the Department of Chemistry, Prince of Songkla University.

\section{References}

1) S. Iijima, Nature, 354, 56-58 (1991).

2) Z. Wang, X. F. Qian, J. Yin and Z. K. Zhu, Langmuir, 20, 3441-3448 (2004).

3) Q. P. Ding, Q. Q. Cao, H. B. Huang, S. G. Yang, X. N. Zhao and Y. W. Du, J. Phys. D: Appl. Phys., 39, 46-49 (2006).

4) Z. W. Dong, C. F. Zhang, H. Deng, G. J. You and S. X. Qian, Mater. Chem. Phys., 99, 160-163 (2006). 
5) Z. Q. Zhu and J. Zhou, Int. J. Miner. Metall. Mater, 17, 80-85 (2010).

6) X. L. Hu, Y. J. Zhu and S. W. Wang, Mater. Chem. Phys., 88, 421-426 (2004).

7) Z. Jingwei, Z. Pengli, L. Zhiwei, C. Jianmin, W. Zhishen and Z. Zhijun, Nanotechnology, 19, 165605 (2008).

8) H. M. Cheng, H. C. Hsu, S. L. Chen, W. T. Wu, C. C. Kao, L. J. Lin and W. F. Hsieh, J. Cryst. Growth, 277, 192-199 (2005).
9) Z. Huang, D. Yan, M. Yang, X. Liao, Y. Kang, G. Yin, Y. Yao and B. Hao, J. Colloid Interface Sci., 325, 356-362 (2008).

10) J. Zhang, L. D. Sun, C. S. Liao and C. H. Yan, Chem. Mater., 14, 4172-4177 (2002).

11) G. H. Lee and M.-S. Kim, J. Ceram. Soc. Japan, 118, 269-271 (2010).

12) X. Zhao, Z. Chen, Y. Luo and L. Wang, Solid State Commun., 147, 447-451 (2008). 